\title{
A multimodalidade como via de análise: contribuições para pesquisas em aquisição de linguagem
}

\author{
Multimodality as a way of analysis: contributions to language acquisition research
}

\section{Andressa Toscano Moura de Caldas Barros de Almeida ${ }^{1}$, Marianne Carvalho Bezerra Cavalcante ${ }^{1}$}

Doutoranda em Linguística pelo PROLING (Programa de Pos-Graduação em Linguistica) Linguística pela mesma instituicão. Desenvolve pesquisas em aquisição de linguagem oral com Eco em prosódia e multimodalidade. E-mail: dssatoscano@gmail.com Professora Adjunta da Universidade Federal da
RESUMO: Considera-se a multimodalidade como constitutiva da linguagem e como lócus de análise em aquisição. Assim, a multimodalidade refere-se às modalidades de uso da língua (fala, gesto, olhar) que coatuam na produção linguística com vistas à interação. Além disso, elege-se a prosódia, por ser elemento da fala, como copartícipe dessa matriz, tanto por se constituir como uma via privilegiada do engajamento da criança no diálogo e nos processos de subjetivação, quanto por ser um fator coesivo na organização da forma fônica e nos princípios de estruturação fonológica (SCARPA, 1988). 0 objetivo deste artigo é mostrar como a prosódia e os gestos funcionam para compor a matriz gesto-fala de uma criança em processo de aquisição de linguagem, tendo como ponto de partida a proposta de Kendon $(1972,1980)$ e McNeill $(1985,1992)$ em que gesto e fala são indissociáveis, por representarem um sistema único. Para ilustrar nosso estudo, apresentaremos recortes de dados de uma díade mãe-criança filmados longitudinal e naturalisticamente, dos 6 aos 24 meses de vida da criança, que foram tratados no software PRAAT. Os dados mostraram que, mesmo ainda pequena, a criança faz uso de instâncias multimodais para fins de interação com seus pares, corroborando a ideia de que gesto e fala são partes de uma mesma matriz de significado.

Palavras-chave: Aquisição de linguagem; Multimodalidade; Gesto; Prosódia; Interação mãe-bebê.

ABSTRACT: Considering multimodality as part of language, we choose it as a way of analysis in language acquisition. Multimodality refers to the modalities of use of the language (speech, gesture, gaze) that complement one another in linguistic production aiming at interaction. In addition, we chose prosody, for it is an element of speech, as a privileged way of engaging the child in dialogue and subjective processes, and as a cohesive factor in the organization of the phonic form and in the principles of phonological structuring (SCARPA, 1988). For this work, we will show how prosody and gesturefunction to form the gesture-speech matrix of a child in the process of language acquisition. Our point of departure are the proposals of Kendon $(1972,1980)$ and McNeill $(1985,1992)$, in which gesture and speech are inseparable. To illustrate our study, we will present longitudinal and naturalistically recorded data from a mother-child dyad, recorded from 6 to 24 months old of the child and treated using the software PRAAT. Our data showed that even when still small, the child makes use of multimodal instances for the purpose of interaction with their peers, corroborating the idea that gesture and speech are parts of the same matrix of meaning.

Keywords: Language acquisition; Multimodality; Gesture; Prosody; Mother-baby interaction. 


\section{A multimodalidade em aquisição da linguagem}

termo "multimodalidade" é um termo recente que tem ganhado espaço em diversas áreas do conhecimento. Em Aquisição de Linguagem, por exemplo, diz respeito às modalidades de uso da língua (fala, gesto, olhar) que coatuam na produção linguística entre parceiros e que hoje têm sido foco de pesquisas que trazem uma perspectiva multimodal de língua (CAVALCANTE, 1994; ÁVILA-NÓBREGA, 2010; COSTA FILHO, 2011; BARROS, 2012), tendo a relação gesto-fala como pauta de muitos pesquisadores (MCNEILL, 1985, 1992, 2000; MCNEILL et al. 2002; GOLDIN-MEADOW, 2006, 2009; BATES e DICK, 2002).

No entanto, para que a multimodalidade seja entendida, é preciso compreender que pesquisas sob esta perspectiva têm uma noção de lingua(gem) como uma instância multimodal. Ou seja, lingua(gem) não é apenas a fala, o gesto ou olhar analisados de forma isoladas, mas o conjunto formado por esses elementos. Portanto, é dentro dessa esfera que trabalham os pesquisadores da multimodalidade em aquisição da linguagem, sob uma perspectiva que não considera apenas o que é dito pela fala como veículo de interação, mas sim, o conjunto de elementos que dão à interação um sentido mais amplo e completo. Assim, neste trabalho, partiremos da concepção de linguagem como multimodal e partilharemos da ideia de McNeill (1985) de que gesto e fala formam um sistema único baseado no mesmo processo mental e que existem imbricações entre eles que ocorrem nos níveis discursivo, sintático, semântico e prosódico.

\section{Elementos multimodais em aquisição da linguagem}

Como vimos anteriormente, os gestos, a fala e o olhar são os elementos que compõem a matriz multimodal da comunicação. Ao longo deste trabalho, definiremos e analisaremos dois desses elementos (gesto e fala) e assumiremos o risco de deixar o terceiro elemento (olhar) à margem da discussão neste trabalho, uma vez que não o privilegiamos neste estudo. Sugerimos, entretanto, a leitura de Tomasello (2007), Ávila-Nóbrega (2010) e Costa Filho (2011) a esse respeito.

Vejamos, então, o que são os gestos e a prosódia em multimodalidade.

\subsection{Gestos}

Desde os anos de 1970 cientistas do desenvolvimento têm investigado associações entre desenvolvimento linguístico e alguns aspectos de atividades manuais, especialmente gestos comunicativos e simbólicos (BATES e DICK, 2002). Dessa forma, o estatuto do(s) gesto(s) em aquisição de linguagem vem sendo discutido por diversos autores (CAVALCANTE; 1994; ÁVILA-NÓBREGA, 2010; GOLDIN-MEADOW, 2006, 2009; FONTE; BARROS; CAVALCANTE e SOARES, 2014) e tem sido pauta de pesquisas atuais. Mas, antes de entrarmos nesta discussão, precisamos definir o que é um gesto.

Com relação ao uso dos gestos e da linguagem verbal e não verbal, Souza e Faria (2010) apontam a perspectiva de Kerbat-Orecchioni (1990), em que "o gesto faz parte da linguagem não verbal a qual permeia todos os nossos enunciados verbais (...)". “Os elementos verbais e os não verbais formam um conjunto, já que na interação ambos podem se encontrar e se relacionar em harmonia" (SOUZA e FARIA, 2010, p. 138).

É interessante destacar a posição adotada pelas autoras, já que para elas gesto e fala não formam uma única matriz de significação, isto é, podem apenas ocorrer em harmonia, em complementaridade. Contrários a isso, para nós os elementos vocais e gestuais são constitutivos de um único sistema, que se estabelece na matriz multimodal, sendo impraticável pensar nesses elementos separadamente. 
Kendon (2000) defende a organização dos gestos como um processo dado mediante a produção de fala que esses gestos acompanham, construindo assim papéis imbricados no processo de aquisição da linguagem. Desse modo, podemos entender que os gestos e a fala compõem um mesmo processo e que corroboram para uma mesma finalidade significativa.

Ainda com relação aos gestos, de Ruiter (2000, p. 284) explica que "os gestos são movimentos espontâneos do corpo que ocorrem durante a fala e podem parecer para representar aspectos de tópicos da fala".

Assim, partimos da premissa de que gesto e fala formam um conjunto que não pode ser dissociado. Essa perspectiva se baseia no funcionamento multimodal da língua (MCNEILL, 1985) e propõe que gesto e fala estão agregados a uma mesma matriz de produção e significação, ou seja, constituem um único sistema linguístico.

McNeill $(1985,2002)$ diz que a palavra "gesto" recobre uma multiplicidade de movimentos comunicativos, principalmente os de mãos e braços. Já Quek e colaboradores (2006) trazem a ideia de gesto em um sentido mais amplo, que inclui não só movimento de mãos, mas também expressão facial e troca de olhares, e tudo isso será considerado gesto.

Entendendo que troca de olhares compõe outra instância dentro da multimodalidade, assumiremos a postura adotada por McNeill de que gestos compreendem movimentos de mãos e braços e nos basearemos na nomenclatura proposta por Kendon (1982), e organizada por McNeill (1992, 2000) para a classificação de diversos gestos. Assim, no "continuum de Kendon", como ficou conhecido, temos a gesticulação, os gestos preenchedores, os emblemas, as pantomimas e os sinais. Vejamos a definição de cada um deles:

A gesticulação é descrita como aqueles gestos que acompanham o fluxo de fala. Sendo o tipo mais frequente no uso diário e cobrindo uma gama de usos e variedades, é produzida principalmente com os braços e as mãos, mas não é restrita a essas partes do corpo, já que a cabeça, as pernas e os pés também podem aparecer como gestos. A gesticulação combina tanto universais quanto traços linguísticos específicos de uma comunidade.

Os gestos preenchedores são descritos por Mcneill como parte da sentença. $O$ termo 'speech-framed gestures' sugere um gesto que ocupa um lugar na sentença, preenchendo um espaço gramatical, ao invés de acompanhar o fluxo de fala, como a gesticulação.

Já os emblemas são os sinais convencionalizados em uma comunidade, tais como a mão fechada com o polegar para cima ou o sinal de OK. Estes são específicos da cultura, têm formas e significado padrão e variam de lugar para lugar.

As pantomimas são gestos ou sequências de gestos que narram uma história, que simulam uma ação ou objeto, e são produzidos sem fala.

Por fim, os sinais são palavras em uma língua de sinais como LIBRAS. As línguas de sinais têm sua própria estrutura linguística, incluindo padrões gramaticais, morfológicos, etc. Vejamos esta classificação ilustrada no Quadro $1^{1}$ que segue:

Quadro 1 - Continuum de Kendon

\begin{tabular}{|c|c|c|c|c|c|}
\hline & Gesticulação & $\begin{array}{c}\text { Gestos } \\
\text { preenchedores }\end{array}$ & Emblemas & Pantomimas & Sinais \\
\hline Gesto-fala & $\begin{array}{c}\text { Presença } \\
\text { obrigatória } \\
\text { de fala }\end{array}$ & $\begin{array}{c}\text { Presença } \\
\text { obrigatória } \\
\text { de fala }\end{array}$ & $\begin{array}{c}\text { Presença } \\
\text { opcional } \\
\text { de fala }\end{array}$ & $\begin{array}{c}\text { Ausência } \\
\text { obrigatória } \\
\text { de fala }\end{array}$ & $\begin{array}{c}\text { Ausência } \\
\text { obrigatória } \\
\text { de fala }\end{array}$ \\
\hline $\begin{array}{c}\text { Gesto- } \\
\text { propriedades } \\
\text { linguísticas }\end{array}$ & $\begin{array}{c}\text { Ausência de } \\
\text { propriedades } \\
\text { linguísticas }\end{array}$ & $\begin{array}{c}\text { Presença de } \\
\text { propriedades } \\
\text { linguísticas }\end{array}$ & $\begin{array}{c}\text { Presença } \\
\text { de algumas } \\
\text { propriedades } \\
\text { linguisticas }\end{array}$ & $\begin{array}{c}\text { Ausência de } \\
\text { propriedades } \\
\text { linguisticas }\end{array}$ & $\begin{array}{c}\text { Presença de } \\
\text { propriedades } \\
\text { linguísticas }\end{array}$ \\
\hline Gesto- convenções & Não convencional & Não convencional & $\begin{array}{c}\text { Parcialmente } \\
\text { convencionais }\end{array}$ & Não convencional & $\begin{array}{c}\text { Totalmente } \\
\text { convencional }\end{array}$ \\
\hline $\begin{array}{c}\text { Gesto- caráter } \\
\text { semiótico }\end{array}$ & $\begin{array}{c}\text { Global e } \\
\text { sintético }\end{array}$ & $\begin{array}{c}\text { Global e } \\
\text { analítico }\end{array}$ & $\begin{array}{c}\text { Segmentado e } \\
\text { sintético }\end{array}$ & $\begin{array}{c}\text { Global e } \\
\text { analítico }\end{array}$ & $\begin{array}{c}\text { Segmentado e } \\
\text { analítico }\end{array}$ \\
\hline
\end{tabular}

${ }^{1}$ O continuum proposto por Kendon levou em consideração a produção linguística adulta, estruturada Para levar-se em conta dados infantis, o continuum precisa ser adaptado. Para uma discussão a esse respeito, remetemos a Ávila Nóbrega; Cavalcante, 2015. 
Diante do quadro acima, temos quatro instâncias no continuum: gestofala, gesto-propriedades linguísticas, gesto-convenções (se o gesto está presente ou não em dada cultura) e gesto-caráter semiótico (se o significado é determinado pelas partes ou pelo todo). Ao mover da esquerda para direita pelo continnum, vemos que a obrigatoriedade de presença de fala diminui quando observamos as propriedades da gesticulação até os sinais. Assim, a gesticulação é obrigatoriamente acompanhada da fala, mas não tem propriedades linguísticas. Os sinais são obrigatoriamente ausentes de fala, mas têm propriedades essenciais de uma língua.

O novo perfil dos estudos sobre os gestos começa a amadurecer e articular outras discussões, inclusive unificando outros elementos da interação aos gestos. Desse modo, destacamos os estudos desenvolvidos nos Estados Unidos em que podemos encontrar publicações de alguns autores além de David McNeill e Adam Kendon, que discutem a relação multimodal da matriz gesto-fala como mostramos a pouco, tais como: Charles Goodwin e seus trabalhos sobre gestos e afasia, Cynthia Butcher e Susan Goldin-Meadow com seus estudos sobre a produção de palavras com movimentos das mãos na produção linguística infantil.

Na Europa temos trabalhos na Suécia de John Laver e Janet Beck, que pesquisam a relação de elementos como voz, postura e gestos, na França podemos encontrar trabalhos de Isabelle Guaïtella e Jacques Boyer a respeito da relação da voz e dos gestos.

Um forte grupo também tem se fundamentado em estudos multimodais e multissensoriais levando em consideração a interação entre adultos, entre adultos e computadores e entre adultos e crianças. O The MARCS Institute é desenvolvido na Universidade de Sidney e tem como coordenadores Denis Burnhan, Kate Stevens, Chris Daves, André van Schaik e Simeon Simoff.

Tendo em vista as discussões sobre o gesto apresentadas até aqui, destacamos ser relevante a necessidade de considerá-lo como elemento colaborador no processo multimodal de aquisição da produção oral, em que elementos atuam para que as interações linguísticas promovam a passagem da criança à falante de sua língua.

Assim, qual a relação que podemos fazer dessas definições de gesto e a aquisição de linguagem? Pensemos, então, que os gestos são atos comunicativos livres para tomar formas que a fala não pode assumir, ou, para crianças nos primeiros estágios de aquisição, formas que elas ainda não conseguem articular no discurso (GOLDIN-MEADOW, 2009). Em um momento do desenvolvimento em que as crianças têm pouca autonomia em relação ao que conseguem dizer, os gestos oferecem um caminho adicional de expressão, expandindo a gama de ideias que elas são capazes de expressar.

É verdade que sabemos que as crianças exploram a modalidade manual desde muito cedo e, assim sendo, os gestos fornecem um caminho para as primeiras palavras. É interessante perceber que as crianças raramente combinam gestos com outros gestos, mas frequentemente combinam gestos com palavras antes mesmo de começarem a combinar palavras com palavras (GOLDIN-MEADOW e MORFORD, 1985).

Butcher e Goldin-Meadow (2000) observaram três meninas e três meninos longitudinalmente durante a transição do estágio de uma palavra para o de duas palavras. A ideia era explorar se gestos comunicativos formam um único sistema em crianças, assim como formam em adultos. o que acharam foi que inicialmente os gestos tendiam a ser produzidos sem palavras, e, em raras ocasiões, quando produzidos com palavras, a fala era sem sentido e não sincronizada com o gesto. No entanto, as duas características que definem a integração gesto-fala em adultos, a coerência semântica e a temporalidade sincrônica, foram achadas na comunicação infantil no momento e antes do período de duas palavras. Essa pesquisa vem colaborar com a nossa hipótese de que desde cedo gesto e fala estão unidos numa mesma matriz de significação. 
Então, como é possível unir gesto e fala numa mesma matriz de significação? É claro que eles pertencem a modalidades diferentes de expressão, mas estão ligados em alguns níveis e trabalham juntos para apresentar as mesmas unidades semânticas. As duas modalidades não são redundantes, mas sim coexpressivas, o que significa que elas dividem a mesma origem semântica, mas são capazes de expressar informações diferentes (QUEK, 2002).

McNeill $(1985,1992)$ diz que gesto e fala estão ligados a uma mesma matriz de significação e que não podem se dissociar. Nossa outra pergunta então é: por que não? Goldin-Meadow (2006) responde que, quando o gesto é produzido isoladamente e assume todo o fardo da comunicação, ele toma forma de língua (como é o caso dos sinais no continuum de Kendon). Entretanto, quando o gesto é produzido em conjunto, dividindo o fardo da comunicação com a fala, ele toma uma forma não-segmentada, imagística, transmitindo informação que não é dita (na fala).

Diante da noção de gesto adotada neste estudo, passemos agora para o outro elemento multimodal que nos ajudará a entender essa matriz de significação.

\subsection{Prosódia}

Não faz tempo que a prosódia é considerada parte dos estudos linguísticos e, estudos em multimodalidade, principalmente, têm alçado esse aspecto linguístico a um lugar de destaque. Ela é a parte da fonética/fonologia que recobre uma gama variada de fenômenos, resultante, mas não exclusiva, da estruturação, nas línguas, de três características suprassegmentais: altura, duração e intensidade (SCARPA, 1999; BALOG e BRENTARI, 2008).

Segundo Scarpa (1999), são parâmetros acústico-auditivos da produção da fala, constituindo subsistemas suprassegmentais per se com variadas potencialidades distintivas ou significativas nas línguas naturais e que combinados, também são responsáveis pelos subsistemas de ritmo, tom e entonação. Para Cagliari (1992), os elementos prosódicos podem, portanto, ser subdivididos em grupos, de acordo com dinâmica de fala (duração, pausa, tempo, ritmo, acento, entre outros), melodia da fala (tom, entonação, tessitura) e qualidade de voz (volume, registro, qualidade de voz).

Se pensarmos em aquisição de linguagem, tanto trabalhos acerca de percepção quanto os que tratam de dados de produção (SCARPA 1999, 2007; CAVALCANTE, 1999, 2015) têm demonstrado que a criança é sensível a essas facetas da prosódia na entrada para a linguagem. Logo, existem ainda indícios apontados na literatura de aquisição de que pistas prosódicas orientam a criança na percepção, no processamento da fala dirigida (ou não) a ela desde os primeiros meses de vida, bem como na interpretação dos enunciados da criança pelo outro. As pesquisas em aquisição de linguagem, sobretudo em aspectos prosódicos da fala da criança ou da fala materna dirigida a ela (CAVALCANTE, 1999, 2015), têm sido de grande relevância para a área. Dentre algumas análises, é fato que a prosódia é um espaço privilegiado da interface entre componentes linguísticos (SCARPA, 2009) e é através de pistas prosódicas que o infante se estrutura na língua.

Neste artigo, a relevância da prosódia se dá a partir do papel atribuído a esse recurso em aquisição da linguagem, que consiste na compreensão da interação social do bebê com seus pares, por meio de listagens de parâmetros prosódicos presentes no input, bem como pelas modificações de tais parâmetros na fala dirigida à criança. Além disso, tanto se constituem como uma via privilegiada do engajamento da criança no diálogo e nos processos de subjetivação, quanto constitui um fator coesivo na organização da forma fônica e nos princípios de estruturação fonológica (SCARPA, 1988). Portanto, tomamos a matriz gesto-vocal como nosso objeto de análise, por coatuar na linguagem engajando a criança na interação e guiando-a para a aquisição. 
Propomos então uma tipologia prosódica, considerando quatro momentos do funcionamento da fala na trajetória linguística infantil: balbucio, jargão, primeiras palavras e holófrases e blocos de enunciado (BARROS, 2012). Vejamos então o que significa cada um desses momentos:

O balbucio é definido como a produção de sílabas que têm, tipicamente, o formato consoante vogal, por exemplo [ma, da, ba]. Tais sílabas são muitas vezes repetitivas e ritmadas (LOCKE, 1995). Neste artigo, consideramos o balbucio como uma produção vocal inicial da trajetória linguística infantil.

Os jargões são definidos como longas sequências de sílabas que contêm padrões de acento e entonação variados e variáveis, que aparecem na fala infantil em torno dos 12 ou 13 meses de idade. Essas produções vocais soam como enunciados completos que carregam conteúdo de afirmações ou perguntas, ocorrendo, muitas vezes, concomitantes a palavras reais. No entanto, os jargões não apresentam conteúdo linguístico ou estrutura gramatical (DROMI, 2002).

Scarpa (2007) considera jargão quando o contorno entonacional se estende a uma cadeia de sílabas ou um longo fragmento composto por sílabas ininteligíveis. O balbucio tardio evolui para jargão quando a entonação é considerada mais madura e os contornos são preenchidos por sílabas tipicamente do balbucio, mas reconhecíveis como intenção comunicativa pelos adultos, que sempre lhe atribuem significado de uma frase ou sentença.

O terceiro momento do funcionamento da fala definido nessa proposta é o das primeiras palavras reconhecíveis. Assim, consideramos nesse período as produções infantis contendo enunciados de uma palavra, que já nem são balbucios nem puramente jargões, visto que as consideramos reconhecíveis na língua adulta e interpretáveis pelo interlocutor.

As produções das primeiras palavras da criança indicam mudança nos contornos entoacionais, que foram constituídos por mais variações de altura. Essas variações de altura são reconhecidas como diferentes intenções comunicativas: pergunta, afirmação, pedido, etc. e que são recorrentes e produtivas e não mais ou menos efêmeras como os balbucios e jargões. Nessas primeiras palavras, encontramos sequências mais curtas em comparação às do jargão e um padrão silábico reconhecido como fazendo parte de um léxico primitivo.

Definimos o período que chamamos de blocos de enunciado como o momento em que a criança alterna a produção de holófrases com enunciados completos. Notamos em nossos dados que nesse momento do processo aquisicional a criança já é capaz de fazer pedidos, perguntas e produzir respostas mais longas com significado completo, superando os enunciados holofrásticos. Notamos que a partir de um ano e meio a criança começa a arriscar-se nesses enunciados mais longos, juntando duas ou mais holófrases.

\section{Análise}

Como dissemos anteriormente, nos basearemos na tipologia gestual proposta por McNeill $(1985,1992)$ e também na noção de prosódia discutida no segmento anterior, para justificar como a matriz gestuo-vocal se constitui na interação mãe-criança e também para fundamentar nossas análises. Nossos dados foram extraídos de um corpus do LAFE, filmado longitudinalmente e em situação natural na casa da díade.

Para esta análise, selecionamos alguns recortes da filmagem que ilustram a matriz gesto-fala e submetemos ao PRAAT para a obtenção das figuras vocais.

\section{Recorte 1 (criança - 0;10.15)}

Situação: A díade está no quarto brincando de ninar uma boneca e uma caixinha de fita. A criança está com a boneca nas mãos, ninando. A mãe pega a boneca e a nina, em seguida a criança faz o mesmo com a caixinha de fita. 
Figura 1 - V. e a caixinha
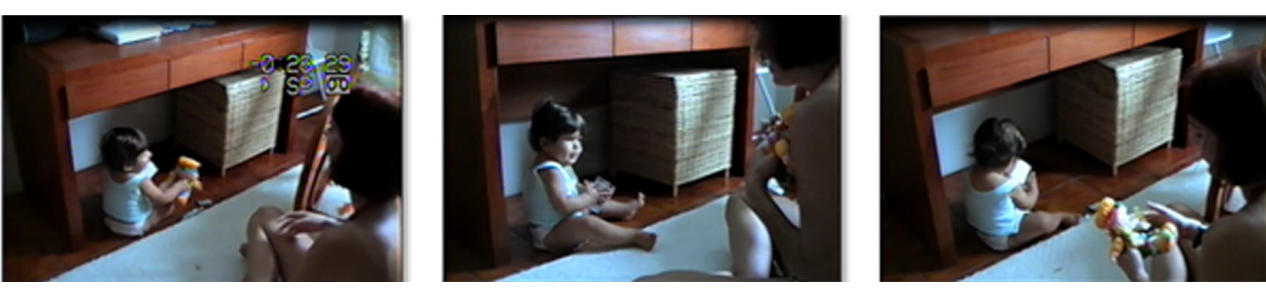

Quadro 2 - Transcrição

\begin{tabular}{|c|c|}
\hline Mãe & Criança \\
\hline Aaa: (pega a boneca) & $\begin{array}{l}\text { Aaa: (com a boneca em mãos, perto ao peito. Depois } \\
\text { entrega a mãe) }\end{array}$ \\
\hline Num é neném & \\
\hline Ааa (risos) & Aаa \\
\hline Bote a neném pra dormir (entrega a boneca a criança) & $\begin{array}{l}\text { (Olha para câmera enquanto bate com as duas } \\
\text { mãos na caixinha) }\end{array}$ \\
\hline Essa caixinha é arretada, né não, essa caixa? & \\
\hline Aaaa: (pega a boneca contra seu peito e nina) & Aaa (pega a caixinha e balança) \\
\hline
\end{tabular}

Segundo a tipologia gestual do continuum de Kendon, tanto mãe quanto criança, quando ninam a boneca ou a caixinha de fita, produzem uma pantomima, pois simulam uma ação (de ninar). Tanto a mãe quanto a criança seguram o objeto com as duas mãos e balançam o corpo de um lado para o outro enquanto cantam a música de ninar, que é marcada em nossa cultura. $\mathrm{O}$ que nossos dados mostram, no entanto, é um estranhamento com o que é dito por Kendon/McNeill, já que nos adultos as pantomimas não são acompanhadas de fala. Precisamos destacar, portanto, que vários de nossos dados de pantomimas são acompanhados de vocalização tanto da mãe quanto da criança. Nossa hipótese para esta ocorrência é de que em um contexto de dialogia, a mãe, como parte da díade, faz uso de mais de uma instância multimodal ao mesmo tempo para inserir a criança no diálogo, pois o uso de gestos não convencionais, como os pantomímicos, não fariam sentido para a criança se não estivessem ancorados em outras instâncias como olhar e fala.

Agora, passemos para a tipologia prosódica. Classificaremos o ninar como jargão, uma vez que ele carrega um contorno entonacional reconhecível na língua adulta, apesar de ser uma produção composta por uma sílaba de balbucio (aaa). A produção de V., portanto, não só acompanha o gesto de ninar a caixa, mas também a entonação dada pela própria mãe, como podemos ver nas figuras a seguir:

Figura 2 - Contorno entoacional de V. /aaa/

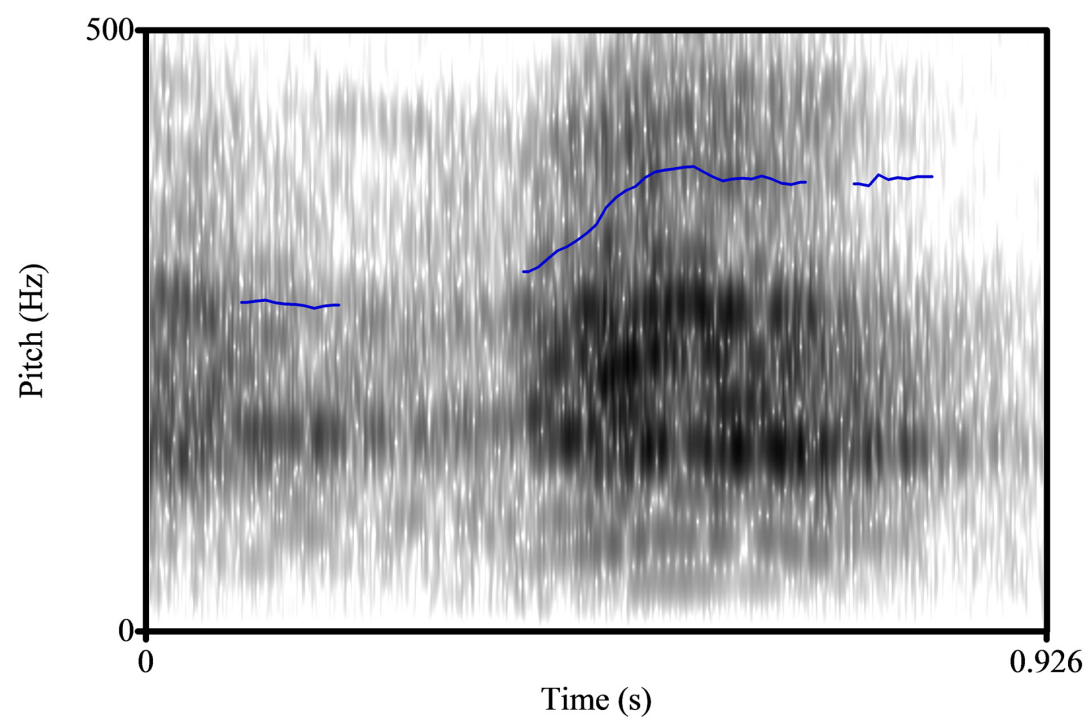


Figura 3 - Contorno entoacional da mãe /aaa/

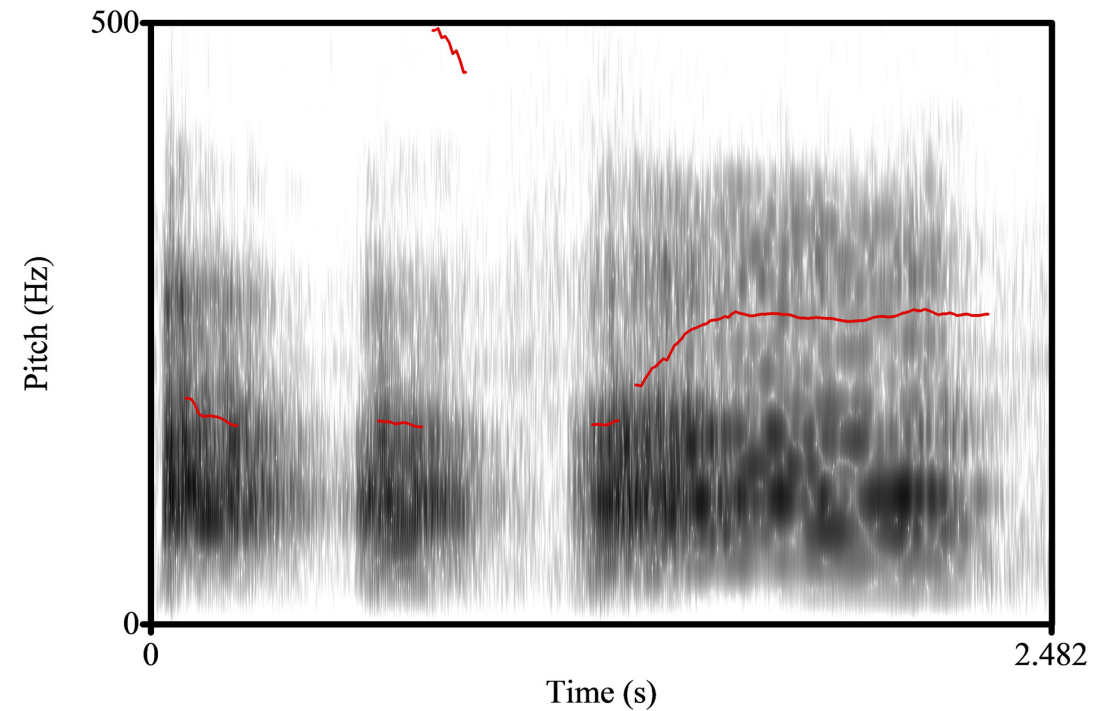

Apesar do âmbito de altura mais elevado que a produção materna, o contorno entonacional de $\mathrm{V}$. segue o mesmo padrão da mãe, com uma curva crescente, como vemos nas figuras acima. Destacamos, então, que nesta situação o jogo dialógico estava completo, pois mãe e criança brincam juntas, engajadas numa mesma ação, em que a criança é convidada a participar da interação. Apontamos também para o fato de ela ser bem pequena (10 meses) e já demonstrar um esboço de um sistema único de significação, onde gesto e fala coatuam, compondo, assim, a matriz multimodal.

\section{Recorte 2 (criança 1;4.6)}

Situação: A díade está no quarto brincando e conversando quando a mãe pede a V. para ela mostrar o pai na revista e a criança aponta. Em seguida a criança folheia a revista apontando e nomeando o que vê.
Figura 4 - V. e a revista
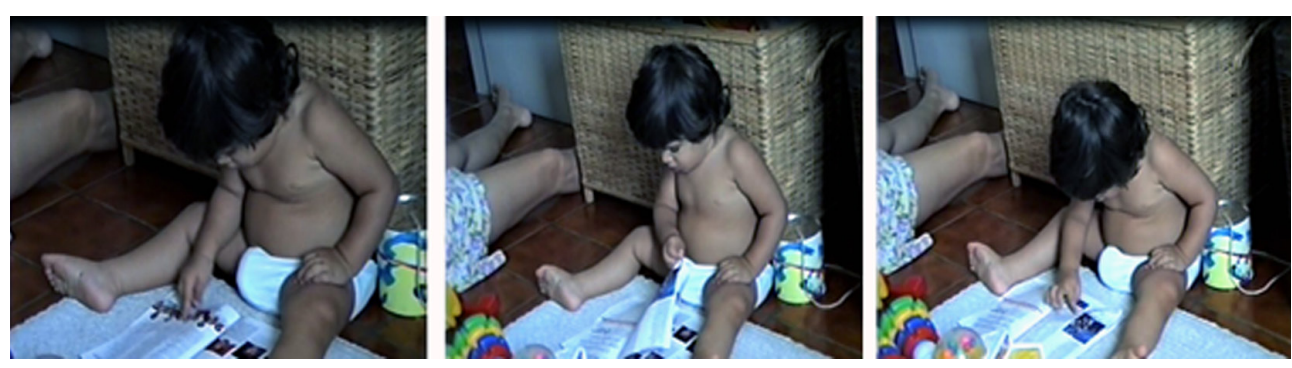

Quadro 2 - Transcrição

\begin{tabular}{|l|l|}
\hline Mãe & Criança \\
\hline $\begin{array}{l}\text { Cadê papai? Mostra papai a Marianne. } \\
\text { Cadê papai? }\end{array}$ & /Uta/ (Olha a revista e aponta) \\
$\begin{array}{l}\text { Hmm? Cuca? Que cuca nada V. ai. Cuca tá lá } \\
\text { na casa de Marianne. }\end{array}$ & /tuta/ (continua a olhar a revista e apontar) \\
\hline
\end{tabular}

O gesto de apontar tem sido amplamente discutido na literatura sobre aquisição de linguagem (CAVALCANTE, 1994; 2010; TOMASELLO, 2007) e trabalhos (GOLDIN-MEADOW, 2009) comprovam que o apontar constitui um passo importante para o desenvolvimento simbólico e abre o caminho para a fala.

A gesticulação está presente em diversos momentos na nossa díade, e o apontar é muito bem marcado pela mãe, que destaca objetos e eventos para V. com o dêitico. Podemos perceber, então, que na cena descrita acima, gesto e fala formam uma unidade semântica coerente, pois, ao ser questionada a mostrar onde está o pai na revista, $\mathrm{V}$. prontamente aponta para alguém na revista. Embora o que ela produza oralmente não seja papai, ela interage com a mãe, entendendo o que sua mãe pediu para ela fazer e dando uma resposta satisfatória em troca. 0 interessante a se destacar nesse recorte 
é, portanto, a combinação apontar + fala quando a criança é questionada a mostrar seu pai.

Vejamos a análise entoacional:

Figura 5 - Contorno entonacional de V. /uta/

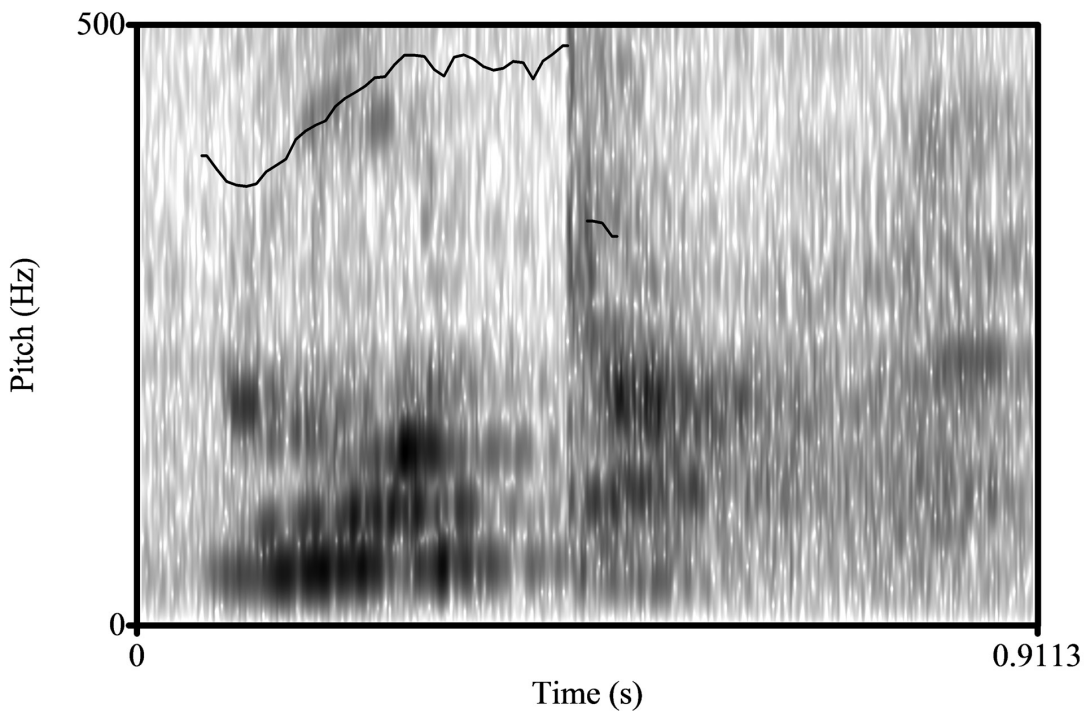

De acordo com a nossa tipologia, classificamos a produção /uta/ como uma holófrase, pois é um enunciado de uma palavra que carrega um sentido completo. Destacamos, portanto, a curva entonacional dessa produção, que é uma curva ascendente, característico das produções enfáticas.

O que este primeiro dado nos mostra é que nesta interação já conseguimos vislumbrar a matriz gestuo-vocal se constituindo e compondo um sistema único de significação.

\section{Recorte 3 (criança - 1;11.28)}

Situação: Esta é uma situação de brincadeira. A díade está interagindo na sala, brincando de tomar café, que está quente. V. oferece o café à mãe que não quer e reclama que está doendo a barriga por $V$. estar sentada em cima dela. V senta no chão e volta a oferecer o café. A mãe recusa de novo, V. vira então e oferece para o observador/pesquisador que também recusa. V. então volta a oferecer a sua mãe.

Figura 6 - V. e a brincadeira
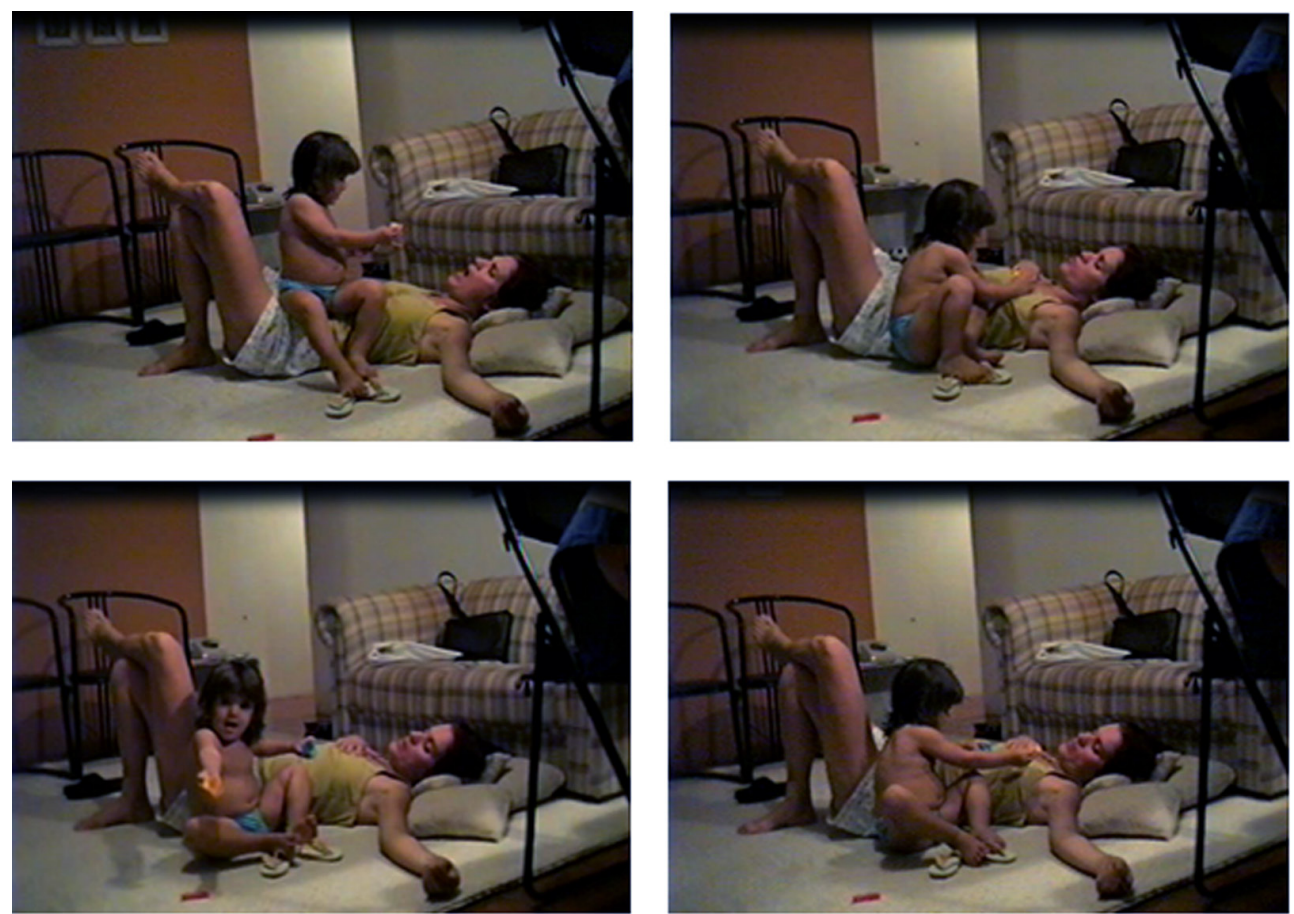
Quadro 3 - Transcrição

\begin{tabular}{|l|l|}
\hline Mãe & Criança \\
\hline Eeeeita! & $\begin{array}{l}\text { Tá quente! (estica o braço em direção à mãe com a } \\
\text { xícara na mão) } \\
\text { Tí a barriga de mamãe vitória, ai ai ai ai } \\
\begin{array}{l}\text { Tá quente? Eu não aguento mais café, tou com a } \\
\text { barriga muito cheia. }\end{array}\end{array}$ \\
$\begin{array}{l}\text { Marianne também não quer não, tá com a barriga } \\
\text { muito cheia. }\end{array}$ & $\begin{array}{l}\text { Toma (Vira o corpo, e com braço esticado, oferece } \\
\text { ao observador) }\end{array}$ \\
$\begin{array}{l}\text { Ou meu deus, quero. Só mais uma. Só mais uma tá } \\
\text { certo? Vou tomar. }\end{array}$ & $\begin{array}{l}\text { quer? (vira o corpo de volta para a mãe e oferece o } \\
\text { "cafente"). }\end{array}$ \\
\hline
\end{tabular}

Diante desta cena temos mais um exemplo de gesticulação, mas dessa vez sem o gesto de apontar. Como vimos, a gesticulação é o gesto que acompanha o fluxo de fala, sendo o tipo mais frequente no uso diário e combina tanto universais quanto traços linguísticos específicos de uma comunidade. Assim, em nossa comunidade é habitual oferecer algo a alguém esticando o braço com o que está sendo oferecido em direção ao interlocutor. 0 que destacamos nesta cena, portanto, é a destreza com que V. interage com suas duas interlocutoras (mãe e observadora) ao oferecer tanto oralmente quando diz "toma" e "quer", quanto gestualmente ao se virar para uma e para outra com o braço esticado e a xícara de café na mão. Na análise entoacional do "toma", que classificamos como um enunciado de uma palavra, temos uma entonação ascendente-descendente, própria das afirmativas, como vemos na imagem a seguir:
Figura 7 - Contorno entoacional de V. /toma/

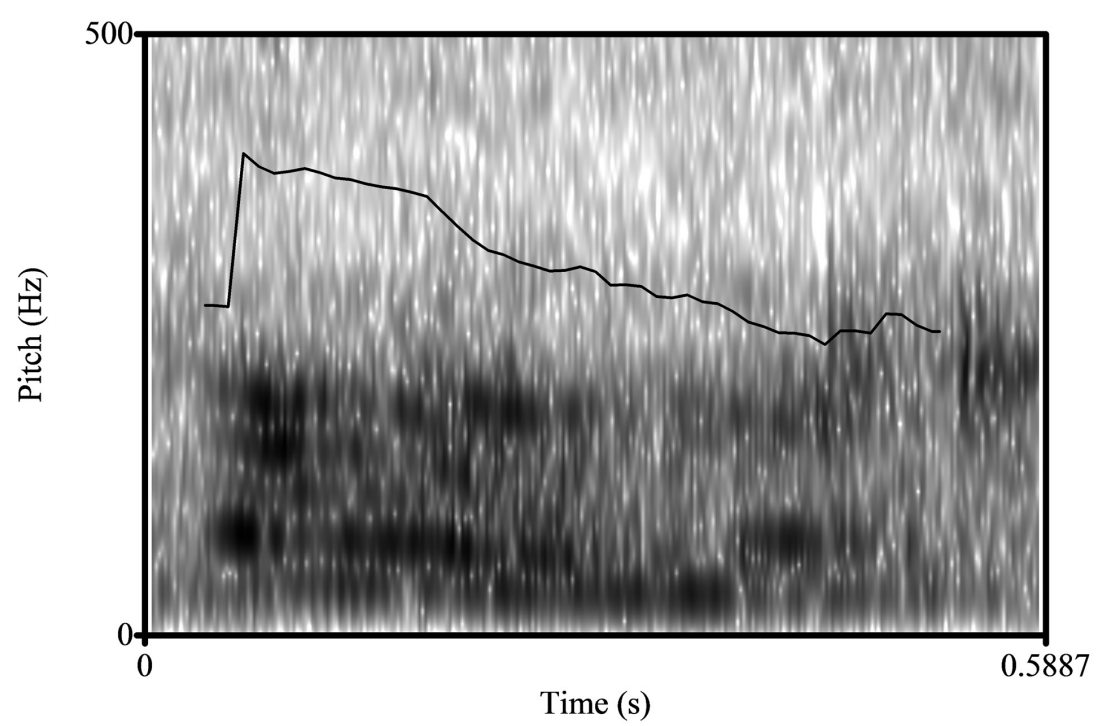

Deste recorte destacamos, portanto, a consolidação da matriz gesto-fala, pois ao oferecer V. não faz uso apenas do elemento fala, mas complementa sua interação com a gesticulação, fazendo com que a matriz sirva ao propósito de interação.

\section{Algumas considerações}

Buscamos mostrar nesse artigo como a instância multimodal (gesto e fala) funciona em crianças em fase de aquisição de linguagem e para que isso fosse possível lançamos mãos de uma tipologia gestual proposta por Kendon e McNeill e a adaptamos para as crianças, visto que as pesquisas deles se voltam para os adultos. 
É pertinente destacar que em nossos dados encontramos um ponto de divergência com a proposta dos autores, pois as pantominas são produzidas com presença de fala, enquanto no continuum de Kendon, pantominas têm ausência obrigatória de fala. Nossa hipótese para isto é a de que, em situação dialógica, a mãe como parte da díade, faz uso de mais de uma instância multimodal ao mesmo tempo para inserir a criança no diálogo, pois o uso de gestos não convencionais como os pantomímicos não faria sentido para a criança se não estivessem ancorados em outras instâncias como olhar e fala.

Baseamo-nos também em conceitos prosódicos para que análises entoacionais da fala pudessem ser feitas e utilizamos a proposta de trabalhos anteriores (BARROS, 2012; FONTE e CAVALCANTE et al., 2014) de estágios de desenvolvimento entoacional, a fim de observar se mesmo em estágios iniciais a criança já trabalha com a matriz gesto-fala. Nossos dados mostraram que, mesmo ainda pequena, a criança faz uso de instâncias multimodais para fins de interação com seus pares, corroborando então os dados apresentados por Butcher e Goldin-Meadow (2000) em que crianças apresentaram gesto e fala integrados numa mesma matriz de significação.

\section{Referências}

ÁVILA-NÓBREGA, Paulo Vinícius. Dialogia mãe-bebê: a emergência do envelope multimodal em cenas de atenção conjunta. 2010. 165f. Dissertação (Mestrado em Linguística) - Universidade Federal da Paraíba, João Pessoa.

ÁVILA-NOBREGA, Paulo Vinícius; CAVALCANTE, Marianne Carvalho Bezerra. O envelope multimodal em aquisição de linguagem: momento do surgimento e pontos de mudanças. In: CAVALCANTE, Marianne Carvalho Bezerra; FARIA, Evangelina Maria Brito de (Org.). Cenas em aquisição da linguagem: multimodalidade, atenção conjunta e subjetividade. João Pessoa: Editora da UFPB, 2015. v. 1, p. 11-44.

BARROS, Andressa Toscano Moura de Caldas; Fala Inicial e Prosódia: do balbucio aos blocos de enunciado. Universidade Federal da Paraíba. Dissertação (Mestrado em Linguística) - Universidade Federal da Paraíba, João Pessoa, 2012.
BATES, Elizabeth; DICK. Frederic. Language, gesture, and the developing brain. Developmental Psychobiology, 40, 293-310, 2002.

BUTCHER, Cynthia; GOLDIN-MEADOW, Susan. Gesture and the transition from oneto two-word speech: when hand and mouth come together. In: MCNEILL, David (Ed.). Language and gesture. Cambridge: Cambridge University Press, 2000.

CAGLIARI, Luiz Carlos. Prosódia: algumas funções dos supra-segmentos. In: BAURRE, M. B. M.; WETZELS, L. W. (Org.). Cadernos de estudos lingüísticos: fonologia do português. Campinas: UNICAMP, IEL, DL, [1992] 1994. p. 137-151.

CAVALCANTE, Marianne Carvalho Bezerra. O gesto de apontar como processo de co-construção nas interações mãe-criança. Dissertação (Mestrado) - Universidade Federal de Pernambuco, 1994

Da voz à língua: a prosódia materna e o deslocamento do sujeito na fala dirigida ao bebê. Tese (Doutorado em Lingüística) - Universidade Estadual de Campinas, Campinas, 1999.

. A natureza do gesto de apontar em aquisição da linguagem: um estudo exploratório. In: CAVAlCANTE, M. C. B. (Org.). Multimodalidade em aquisição da linguagem. João Pessoa: Editora Universitária UFPB. 2010. v. 1, p. 09-40.

Da voz à língua: o manhês na dialogia mãe-bebê. João Pessoa: Editora da UFPB, 2015. v. 500.237p.

DROMI, Esther. Babbling and early words. In: SALKIND, Neil .J. (Ed.). Child development. McMillan psychology reference series. McMillan, 2002.

FONTE, Renata; CAVALCANTE, Marianne Carvalho Bezerra; BARROS, Andressa Toscano Moura de Caldas; SOARES, Paula. A matriz gesto-fala na aquisição da linguagem: algumas reflexões. In: Aquisição, desvios e práticas de linguagem. Editora CRV, 2014.

GOLDIN-MEADOW, Susan. Talking and thinking with your hands. Current directions in psychological science, v. 15, n. 1, 2006.

From gesture to word. In: BAVIN, Edith L. (Ed.). The Cambridge handbook of child language. University of Cambridge Press, 2009.

KENDON, Adam. The study of gesture: some remarks on its history. Recherches sémiotiques/semiotic inquiry, v. 2, p. 45-62, 1982.

LOCKE, John. Desenvolvimento da capacidade para a linguagem falada. In: FLETCHER, Paul; MACWHINNEY, Brian (Ed.). Compêndio da linguagem da criança. Tradução de M. A. G. Domingues. Porto Alegre: Artes Médicas, 1995. 
MCNEILL, David. So, do you think gestures are nonverbal? Psychological Review, v. 92, n. 3, p. 350-371, 1985.

Hand and mind: What gestures reveal about thought. Chicago: University of Chicago Press, 1992.

Gesture and Thought. Chicago: University of Chicago Press, 2005.

QUEK, Francis; MCNEILL, David; BRYLL, Robert et al. Multimodal human discourse: gesture and speech. ACM transactions on computer-human interactions, v. 9, n. 3, p. 171-193, Sept. 2002.

RUITER, Jan. P. de. The production of gesture and speech. In: MCNEILL, David (Ed.). Language and gesture. Cambridge, UK: Cambridge University Press, 2000. p. 284-311.

SCARPA, Ester Miriam. O lugar da holófrase nos estudos de Aquisição da Linguagem. Cadernos de Estudos Linguísticos (UNICAMP), v. 51, p. 187-200, 2009.

A Aquisição da prosódia: dupla face, dupla vocação. In: AGUIAR, Marígia Ana M; MADEIRO, Francisco (Org.). Em-Tom-Ação: a prosódia em perspectiva. Recife: Editora Universitária da UFPE, 2007.

Sons preenchedores e guardadores de lugar: relações entre fatos sintáticos e prosódicos na aquisição da linguagem. In: SCARPA, Ester (Org.). Estudos de Prosódia. Campinas: UNICAMP, 1999.

Learning External Sandhi: evidence for a top-down hypothesis of prosodic acquisition. In: GALA'97 - Conference on Language Representation and Processing, 1997. Proceedings of .... Edimburgo, Escócia, 1997.

Desenvolvimento da intonação e a organização da fala inicial. Cadernos de Estudos Lingüísticos, UNICAMP, v. 14, p. 65-84, 1988.

SOUZA. Wilma Pastor Andrade; FARIA; Evangelina Maria B. O gesto facilitador da produção de sentido no diálogo entre crianças surdas em aquisição da linguagem. In: CAVALCANTE, Marianne C. B.; FARIA, Evangelina. M. B. de; LEITÃO, Márcio (Org.). Aquisição da linguagem e processamento linguístico. João Pessoa: Ed. da UFPB, 2010. p. 135-148.

TOMASELLO, Michael; CARPENTER, Malinda; LISZKOWSKI, Ulf. A new look at infant pointing. Child Development, v. 78, n. 3, p. 705-722, May-June 2007. 